\title{
Anatomopathological Study in BALB/c Mice Brains Experimentally Infected With Toxoplasma gondii
}

Marcos Gontijo da Silva ${ }^{1}$, Ruy de Souza Lino Junior ${ }^{2}$, Tatiane Luiza da Costa ${ }^{3}$, Joanna D’arc Herzog Soares ${ }^{4}$, Waldemar Naves do Amaral $^{5}$, Mariza Martins Avelino ${ }^{6}$ and Ana Maria de Castro ${ }^{7}$

${ }^{1,3}$ Postgraduate program from the Tropical Pathology and Public Health Institute, Federal University of Goias (IPTSP/UFG); ${ }^{2}$ General Pathology Sector from Microbiology, Immunology, Parasitology and Pathology Department (DMIPP) from IPTSP/UFG; ${ }^{4,7}$ Parasitology Sector from DMIPP/IPTSP/UFG; ${ }^{5}$ Gynecology and Obstetrics Department from Medicine School, UFG; ${ }^{6}$ Pediatrics and Puericulture Department from Medicine School, UFG.; Goiânia, GO, Brazil

\begin{abstract}
Toxoplasmosis is one of the most important diseases of the nervous central system, leading to severe symptoms and, many times, irreversible sequelae. This work demonstrated the main anatomopathological lesions caused by Toxoplasma gondii in brains from experimentally infected BALB/c mice. We analyzed 51 cases of mice that developed toxoplasmosis after experimental infection by intraperitoneal inoculation of blood, amniotic liquid and cerebrospinal fluid from fetuses, newly born children and pregnant women with clinical and laboratory signals of toxoplasmosis. In all experiments where we detected the parasite in mice we also detected pathological lesions in the animal brains with great polymorphism between experiments. Edema was the most found lesion in all cases. Besides, it was possible to demonstrate the inflammatory process in $82.4 \%$ of cases and necrosis in $64.7 \%$ of cases, in agreement with the literature that describes severe neurological damage in its hosts.
\end{abstract}

Key-Words: Toxoplasmosis, experimental histopathology, mice brains.

Inflammatory and infectious diseases of the central nervous system (CNS) represent an important group of human diseases. Severe clinical signals, many times incompatible with life, can be determined by different etiologies. Toxoplasma gondii, a protozoan, is an important pathogen that determines high levels of human mortality [1].

The clinical evolution of human toxoplasmosis in immunocompetent patients is normally of good prognosis and the infection is in most cases asymptomatic [1,2]. However, in immunosupressed patients the most common clinical signals and symptoms are lymphadenitis and fever, accompanied by asthenia and myalgia [3]. Amongst the symptomatic forms, the neurological involvement is the most common, observed as encephalitis or meningoencephalitis with unspecific symptoms [3]. The beginning may be marked by cephalalgia, somnolence and behavioral changes, during from days to weeks, followed by coma, convulsions, pyramidal or cerebellar syndrome, ophthalmologic paralysis and psychic alterations [3-8]. The encephalitis usually is diffuse and focal lesions leading to localized manifestations are rarely observed [5,7].

The main anatomopathological signals observed in human being brains infected with $T$. gondii, indicative of expansive lesion of the central nervous system, are: diffuse congestion and edema of the encephalic parenchyma and coagulative necrosis with varied sizes, in different evolutionary stages and scattered over the white and grey substances [9].

Usually, coagulative necrosis of the brain is liquefactive as in infarcts and it can be associated or not to hemorrhage. It

Received on 27 August 2007; revised 26 January 2008.

Address for correspondence: Dr. Ana Maria de Castro. Laboratory of Biology, Physiology and Immunology of Protozoans from Human Interest. Room 214-IPTSP/UFG. Rua 235 esq/ $1^{\text {a }}$. Av. s/n Setor Leste Universitário, Goiânia Goiás -74605-050. Telephone: 55623521 1840. Fax. 55623521 1837. E-mail: amaria@iptsp.ufg.br. is also found hemorrhage with erythrocytes displayed in the lesion periphery and in other encephalic regions [9].

It is also observed infiltrated macrophages with myelinic residues phagocytized, lymphocytes and plasmocytes. In some regions, the blood irrigation is damaged blocking the circulating monocytes arrival, therefore the necrotic tissue is not phagocytized or eliminated, remaining in the region and, possibly, suffering calcification. In apparent older necrotic areas it is possible to distinguish edema and hemorrhage surrounding the lesion [9].

The most evident lesion in toxoplasmosis are described above, however, the severity of each reported lesion varies according to the strains virulence and to individual immunological response, therefore it is possible to observe different symptoms and lesions in each individual.

This work aimed to describe the anatomopathological lesions in brains from BALB/c mice inoculated with fetal blood, amniotic liquid, newly born blood, cerebrospinal fluid (CSF) and maternal blood from patients with active toxoplasmosis.

\section{Material and Methods}

One hundred and fifty-five samples with suspicion of active toxoplasmosis were led to the Protozoan Laboratory of the Tropical Pathology and Public Health Institute (IPTSP) from the Federal University of Goiás (UFG). From the 155 samples, 65 were fetal blood, 50 were amniotic fluid, 11 were newly born children blood, 12 were CSF and 17 were maternal blood from pregnant and/or with newly born children triaged by the Gynecology, Obstetrics and Pediatrician sectors from Medicine School from UFG in the period from September of 2002 to January of 2005.

The samples mentioned above were centrifuged at 3,000 $\mathrm{RPM} / 10$ minutes and the sediment or erythrocyte mass was inoculated intraperitoneally $(0.2 \mathrm{~mL}$ per animal $)$ with a $1 \mathrm{~mL}$ syringe in groups of three isogenic BALB-c mice, male, weighing $30 \mathrm{~g}$ and with 30 days old of age ( $1^{\text {st }}$ inoculum) from 
the animal facilities of IPTSP. The animals were accompanied for 60 days and, then, sacrificed by cervical dislocation. The macerated brain was reinoculated intraperitoneally in a second group of three BALB/c mice ( $2^{\text {nd }}$ inoculum) accordingly to pre-established protocol [9].

As control it was used a group of five non-infected mice with same age and weight as the mice used in the experiment.

The clinical sings acquired after the inoculation and the encephala were evaluated in relation to encephalic mass/body mass, volume and sulci and gyri shapes.

The encephala from the mice were sectioned with $5 \mathrm{~mm}$ wide and fixed in $70 \%$ alcohol per $24 \mathrm{~h}$ and then transferred to a $10 \%$ tamponade formol solution. After that, the fragments were processed to histological blocks confectioned accordingly to Junqueira (1983) [10]. There were ten histological sections, of each sample, performed with $5 \mathrm{~mm}$ wide. They were stained by hematoxilin-eosin (HE) technique [10].

The sections were examined at light microscope (Olympus CX-31), with the 10, 40 and 100x objectives. In the regions where the parasite was found the following pathological processes were analyzed: necrosis $(\mathrm{N})$, hyperemia (HP), hemorrhage (HM), edema (E) and inflammation (I).

The pathological lesions were classified in qualitative and semi-qualitative ways accordingly to the following parameters: absent, discrete with $25 \%$ of area lesioned, mild with $26 \%$ to $50 \%$ of involvement and severe with more than $50 \%$ of involvement. The results were analyzed by the non-parametric test of Kruskal-Wallis.

This work was approved by the Ethics in Human and Animal Research Committee and was identified in CEOMHA/ HC/UFG with the number 039/02 as well as the term of consent that was considered in accordance with the current ethical principles.

\section{Results}

From the 155 samples, it was possible to visualize the tachyzoite forms or the cysts/pseudocysts of the parasite in $51(33 \%)$ of them, figure I. From the 51 samples where were detected $T$. gondii forms, $15(29.4 \%)$ were from the amniotic liquid, $23(45.1 \%)$ were fetal blood, 4 (7.8\%) from CSF, 4 (7.8\%) from newly born blood and $5(9.8 \%)$ from maternal blood.

\section{Macroscopic Analysis}

The main signs observed in the human material-inoculated animals were: behavioral changes, bristled pelage, lethargy, discrete increase of the abdominal volume, loss of weight, anorexia and weeping. In the encephala of the animals with apparent infection it was observed the discrete increase of weight and volume, widening of gyri and decreasing of sulci. The leptomeninges were thick and opaque.

The control animals did not show clinical alterations or lesions observed in the experiment animals. Their encephala presented apparently normal in volume and colouring. Microscopic Analysis
The histopathological findings were of varied nature and intensity, distributed mainly through the encephalic tissue and cerebellum. The anatomopathological analysis showed lesions in different intensities, types and shapes as observed in Table 1.

The most found pathological lesion was edema, which was present in $51(100 \%)$ cases, followed by parenchymal hemorrhage in $49(96.10 \%)$, parenchymal hyperemia in 47 $(92.20 \%)$, meningeal hemorrhage in $45(88.20 \%)$, inflammation in $42(82.40 \%)$, meningeal hyperemia in $36(70.59 \%)$ and coagulative necrosis in $33(64.70 \%)$ of the samples (Table 1, Figure 2).

The inflammation and parenchymal hemorrhage were the most common lesions found as severe involvement, both present in this condition in $12(23.60 \%)$ cases. The parenchymal hyperemia was the mildest lesion present, found in $29(56.90 \%)$ cases. The parenchymal hemorrhage was the most common lesion present as a discrete involvement, what was observed in $21(41.20 \%)$ cases (Table 1$)$.

\section{Fetal Material}

The pathological lesions with greater frequency in encephala from mice inoculated with amniotic liquid were parenchymal hyperemia, edema and inflammation manifested in a mild intensity and the other lesions observed were of discrete intensity. In animals inoculated with fetal blood the coagulative necrosis and inflammation manifested in a discrete intensity while the other lesions found presented itself in a mild intensity (Table 2).

\section{Newly Born Material}

The pathological lesions found with greater frequency in the encephala from mice inoculated with newly born blood were parenchymal hemorrhage and meningeal hemorrhage in a discrete way while inflammation was of severe intensity and other lesions were of mild intensity. In encephala inoculated with CSF the parenchymal hemorrhage, the meningeal hemorrhage and edema were of mild intensity and the other lesions of discrete intensity (Table 2).

Pregnant women material: The pathological lesion with greater frequency in encephala from mice inoculated with maternal blood was parenchymal hemorrhage, which manifested itself with severe intensity while the other lesions were of mild intensity (Table 2).

\section{Control Animals}

In encephala from control animals it was observed edema and meningeal hemorrhage in a discrete intensity. The other lesions were not observed.

In most cases the edema found was diffuse through the encephalic parenchyma.

In the 33 cases where coagulative necrosis was found the lesions were of varied size, in different evolutive stages and disseminated through the white and gray matter. In some areas there was only necrotic tissue and in other areas it was 
Table 1. Anatomopathological lesions in 51 encephala from $T$. gondii-infected mice, 60 days after intraperitoneal inoculation

\begin{tabular}{|c|c|c|c|c|c|c|c|c|c|c|c|c|c|c|}
\hline \multirow[t]{2}{*}{ Intensity of process } & \multicolumn{2}{|r|}{ I } & \multicolumn{2}{|c|}{$\mathbf{C N}$} & \multicolumn{2}{|c|}{$\mathbf{E}$} & \multicolumn{2}{|c|}{ МНM } & \multicolumn{2}{|c|}{ PHM } & \multicolumn{2}{|c|}{ MHP } & \multicolumn{2}{|c|}{ PHP } \\
\hline & $\mathbf{N}$ & $\%$ & $\mathbf{N}$ & $\%$ & $\mathbf{N}$ & $\%$ & $\mathbf{N}$ & $\%$ & $\mathbf{N}$ & $\%$ & $\mathbf{N}$ & $\%$ & $\mathbf{N}$ & $\%$ \\
\hline Absent & 9 & 17.6 & 18 & 35.3 & - & - & 6 & 11.8 & 2 & 3.9 & 15 & 29.4 & 4 & 7.8 \\
\hline Discrete & 15 & 29.4 & 15 & 29.4 & 12 & 23.5 & 18 & 35.3 & 21 & 41.2 & 7 & 13.7 & 11 & 21.6 \\
\hline Mild & 15 & 29.4 & 12 & 23.5 & 34 & 66.7 & 17 & 33.3 & 16 & 31.4 & 23 & 45.1 & 29 & 56.9 \\
\hline Severe & 12 & 23.6 & 6 & 11.8 & 5 & 9.8 & 10 & 19.6 & 12 & 23.5 & 6 & 11.8 & 7 & 13.7 \\
\hline Total & 42 & 82.4 & 33 & 64.7 & 51 & 100 & 45 & 88.2 & 49 & 96.1 & 36 & 70.6 & 47 & 92.2 \\
\hline
\end{tabular}

I - inflammation, CN - coagulative necrosis, E - edema, MHM - meningeal hemorrhage, PHM - parenchymal hemorrhage, MHP meningeal hyperemia, PHP - parenchymal hyperemia, $\mathrm{N}$ - number of positive cases. p $\mathrm{t} 0.05-\mathrm{KW}$.

Table 2. Intensity of general pathological processes in encephala from Toxoplasma gondii-infected mice 60 days after inoculation

\begin{tabular}{lcccccc}
\hline & AL & FB & NBB & CSF & SgM & CN \\
& N=15 & N=23 & N=4 & N=4 & N=5 & N=5 \\
\hline Edema & + & + & + & + & + & + \\
Meningeal hemorrhage & + & + & + & + & + & + \\
Parenchymal hemorrhage & + & + & + & + & ++ & + \\
Meningeal hyperemia & + & + & + & + & + & - \\
Parenchymal hyperemia & + & + & + & + & + & - \\
Inflammation & + & + & ++ & ++ & + & - \\
Coagulative necrosis & + & + & + & + & + & - \\
\hline
\end{tabular}

+ discrete, ++ mild, +++ severe, $\mathrm{AL}$ - amniotic liquid, FB - fetal blood, NBB - newly born blood, CSF - cerebrospinal fluid, MB

- maternal blood, NC - negative control. p t 0.05 - KW.

Figure 1. Evolutive forms (arrow) of Toxoplasma gondii, found in encephala of experimentally infected mice, stained by hematoxilin-eosin technique: A - tachyzoite (100x), B - pseudocyst (40x) and C - cysts (100x)

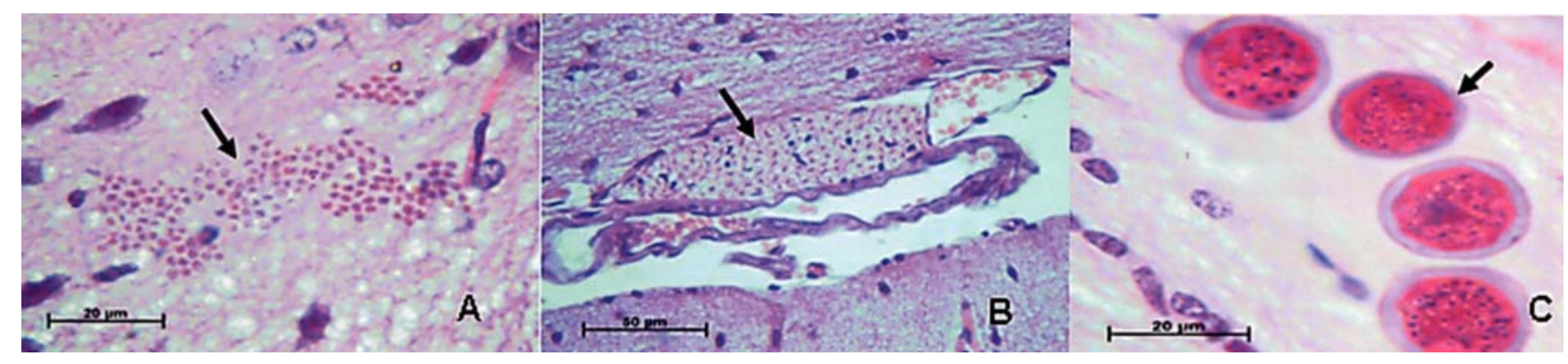

associated to hemorrhagic areas or erythrocytes at the periphery of the lesion, and in other sites, besides the necrosis associated or not to hemorrhage, it was visualized macrophagic infiltrate with myelinic rests phagocytized, lymphocytes and plasmocytes. In areas where the necrosis presented itself older it was possible to visualize edema and hemorrhagic concentric areas, which seemed to surround the necrotic tissue. Some vessels presented predominantly mononuclear infiltrate and other vessels showed at their walls cellular exudate of varied intensity formed mainly by mononuclear cells.

At 100x objective under immersion, in the necrotic areas there were fibers with myelinic lesions characterized as rarefied due to disorganization of myelin, which presented partially destroyed or in concentric rough groups. Beyond the lesioned fibers, there were other fibers apparently without morphological lesions. In some cases there was meningitis more intense in regions where pia mater and arachnoid covered the necrotic parenchymal sites. In these sites the inflammatory process was characterized by congestion and cellular infiltrate constituted mainly by mononuclear cells and neutrophils in less number. In the rest of the meninges the inflammation was of discrete intensity.

In HE staining the $T$. gondii forms, tachyzoites and pseudocysts, were easily identified. Tachyzoites were more frequent than pseudocysts. In few cases, it was possible to detect parasites in the necrotic sites. 
Figure 2. Anatomopathological analysis with different observed lesions in encephala of experimentally infected mice with Toxoplasma gondii, stained by hematoxilin-eosin technique: A1 - perivascular edema, A2 - tachyzoite forms (40x), B1 parenchymal hyperemia, B2 - tachyzoite forms (10x), C - parenchymal hemorrhage (100x), D1 - meningeal hyperemia, D2 meningeal hemorrhage (40x), E1 - coagulative necrosis, E2 - inflammation (40x), F1 - inflammation and F2 - coagulative necrosis (100x)

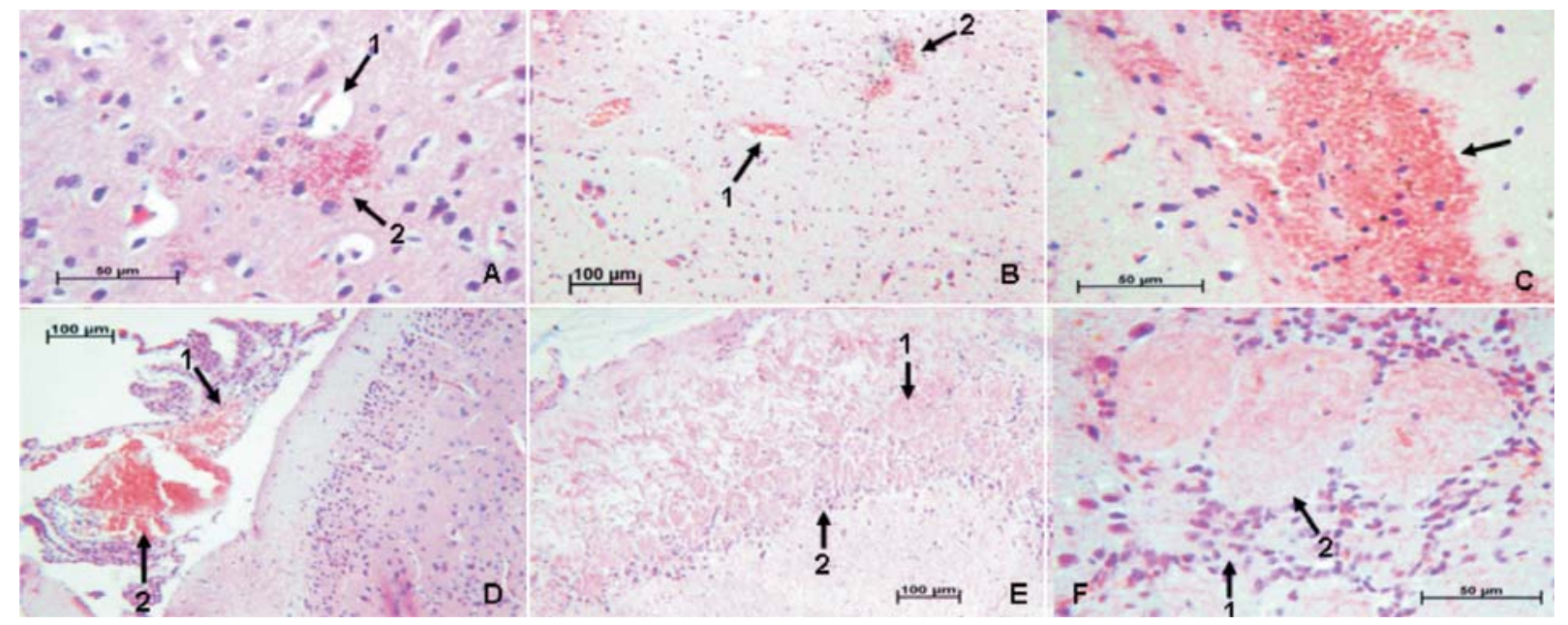

\section{Discussion}

T. gondii has been responsible for human infections with bad prognosis [11,12]. This infection can be experimentally induced in laboratory animals, especially mice [13-16]. Therefore the experimental infection has helped to understand the pathological and physiological aspects of this disease considered of great importance to humans.

The behavioral and/or clinical changes such as unspecific encephalopathy, diffuse meningoencephalitis or even expansive lesions observed in animals in this work can result from the ischemic or anoxic injury caused by the parasite [17,18]. The decrease in the oxygen supply of 25 to $40 \%$ from normal in an ischemic site is tolerated by the encephalon for a short period of time. Oxygen decrease leads to death and cellular lysis [19-21].

According to Post et al. (1983) [22], Macedo (1994) [23] and Lazo (1998) [24], the meningoencephalitis by Toxoplasma is located initially in the white matter and as the process evolves it reaches the gray matter. In the present study it was observed lesions equally distributed through white and grey substances, indicating that the lesions were in an advanced stage of development. In this essay, the lesions of encephalic parenchyma were more frequent in meninges accordingly to Navia (1986) [25], Porter (1992) [26] and Post (1983) [22].

We noted that in some necrotic sites it was not possible to observe the hemorrhage, what corroborates with literature data [24] that demonstrate the occurrence of this fact in neurotoxoplasmosis patients. In most of the analyzed cases, the detection of the parasite in the vicinities of the lesion was not possible, being in accordance with Lazo (1998) [24]. The necrotic vascular lesions and the thrombosis have been described by Bertoli et al. (1995) [11] and Huang and Chou
(1988) [27] in toxoplasmic encephalitis as frequent and intense, what could explain the necrotic sites without parasites.

We observed that the studied encephala presented lesions in different degrees of intensity and the symptoms detected were reflex of its severity and its location. These differences could be from intrinsic differences of strains.

In all cases analyzed in this study, edema was verified, accordingly to literature data, as the first signal of response from the organism to the parasite, followed by hemorrhage, hyperemia, inflammation and necrosis. Depending on the location and extension of necrosis it can lead to death of the patient and/or cause irreversible sequelae. This work data suggest that the lesions found are diverse, from edema to necrosis, and are directly related to the parasite's presence, in opposition to encephala from control mice, where any lesion encountered in experiment group was not found.

The microscopic lesions found were consistent to the ones reported by other authors which studied lesions in humans $[7,9,11]$. This study confirms the importance of $T$. gondii as a cause of active and severe lesion in the central nervous system.

\section{References}

1. Santana R.M., Andrade F.M., Moron A.F. Infecções TORCH e gravidez. In: Prado F.C., Ramos J., Ribeiro do Valle J. (eds). Atualização terapêutica. $21^{a}$ edição, Artes Médicas, São Paulo, p. 1111-1112, 2003.

2. Wong S.Y., Remington J.S. Toxoplasmosis in pregnancy. Clinical Infectious Diseases 1994;18:853-62.

3. Moron A.F., Carvalho F.H.C., Santana R.M. Toxoplasmose. In: Schor N (eds). Guia de obstetrícia. Manole, São Paulo, p. 485489, 2003.

4. Desguerre I., Pedespan J.M., Buissonnère R., et al. Toxoplasmose cérébrale acquise chez un enfant non immunodéprimé. Archives Françaises Pediatrie 1993;50:339-42. 
5. Khan E.A., Correa A.G. Toxoplasmosis of the central nervous system in non-human immunodeficiency virus-infected children: case report and review of the literature. The Pediatric Infectious Diseases Journal 1997;16:611-8.

6. Lescop J., Brinquini L., Schill H., et al. Encéphalite toxoplasmique diffuse chez un sujet non immunodéprimé. Journal de Radiologie 1995;76:21-4.

7. Townsend J.J., Wolinsky J.S., Baringer J.R., Johnson P.C. Acquired Toxoplasmosis. Archives of Neurology 1975;32:335-43.

8. Triki A., Couvreur J. Les manifestations neuro-méningées de la toxoplasmose acquise. La Tunisie Medicale 1971;49:323-9.

9. Silva L.A., Vieira R.S., Serafini L.N. Toxoplasmose do sistema nervoso central em paciente sem evidência de imunossupressão: relato de caso. Revista da Sociedade Brasileira de Medicina Tropical 2001;34(5):487-90.

10. Junqueira L.C.U. Técnicas Básicas de citologia e histologia. $1^{\mathrm{a}}$ edição, Santos, 1983

11. Bertoli F., Espino M., Arosemena J.R., et al. A spectrum in the pathology of toxoplasmosis in patients with acquired immunodeficiency syndrome. Archives of Pathology and Laboratory Medicine 1995;119:214-24.

12. Couvreur J., Desmonts G., Tournier G., Szusterkac M. Estude d'une série homogéne de 210 cas de toxoplasmose congénitale chez des mourissons âges de 0 a 11 mois et dépistés de façon prospective. Pédiatric Annals 1974;31:815-9.

13. Camargo M.E., Moura M.E.G., Leser P.G. Toxoplasmosis serology: an efficient hemaglutination procedure to detect IgG and IgM antibodies. Revista do Instituto de Medicina Tropical 1989;31:279-85.

14. Frenkel J.K. Toxoplasmose. In: Veronesi R., Foccacic R. Tratado de infectologia. Atheneu, São Paulo, p. 1290-1305, 1997.

15. Beazley D.M., Egerman R.S. Toxoplasmosis. Seminars Perinatology 1998;22(4):332-8.

16. Kawazoe V. Toxoplasma gondii In: Neves DPM, Genaro O, Linardi PM. Parasitologia Humana, $9^{\circ}$ Edição, Atheneu, São Paulo, p. 174-87, 1995.
17. Ketz S.S. The cerebral circulation. In: Fishman AP, Richards DW. Circulation of the blood: men and ideas. Oxford Universit Press, New York, p.703-742, 1964.

18. Nakai H., Yamamoto Y.L., Diksic M. Triple-tracer autoradiograph demonstrate effects of hypoglycemia of rats. Stroke 1988; $19: 764-72$.

19. Bambirra E.A., Barbosa A.J.A. In: Bogliolo Patologia Geral. 5 edição, Guanabara Koogan, Rio de Janeiro, p.1087-102, 1994.

20. Graham S.H., Chen J. Limiting ischemic injury by inhibition of excitatory amino acid release. Journauls Cerebral Blood Flow Metabolism 1993; $13: 88-97$.

21. Rothman S.M., Olney J.W. Glutamate and the pathophysiology of hipoxic-ischemic brain damage. Neurology Annals 1986; 19 : $105-11$

22. Post D.M.J., Chan J.C., Hensley G.T., et al. Toxoplasma encephalitis in Haitian adults with acquired immunodeficiency syndrome: a clinical-pathologic-CT correlation. American Journal of Roentgenology 1983;140:861-8.

23. Macedo V. Toxoplasma. In: Castro LP, Cunha AS, Rezende JM (eds) Protozooses humanas, Fundo Editorial BYK, São Paulo, p. 153-70, 1994.

24. Lazo J.E. Diagnóstico diferencial entre meningoencefalites toxoplásmica e chagásica em pacientes com infecção pelo vírus da imunodeficiência humana. Enfase às alterações morfológicas. Dissertação de Mestrado. Faculdade de Medicina do Triângulo Mineiro, Uberaba, MG, 1995.

25. Navia B.A., Petito C.K., Gold J.W.M., et al. Cerebral toxoplamosis complicating the acquired immune deficiency syndrome: clinical and neuropathological findings in 27 patients. Annals of Neurology 1986;19:224-38.

26. Porter S.B., Sande M.A. Toxoplasmosis of the central nervous system in the acquired immunodeficiency syndrome. New England Journal of Medicine 1992;327:1643-8.

27. Huang T.E., Chou S.M. Oclusive hypertrophic arteritis as the cause of discrete necrosis in CNS toxoplasmosis in the acquired immunodeficiency syndrome. Human Pathology $1988 ; 19: 1210-4$. 